\title{
The Effects of Standardized Ginkgo Biloba Extracts (GBE) on Subjective Cognitive Decline (SCD) in Middle-Aged Adults: A Review
}

\author{
Joerg Gruenwald ${ }^{*}$, Anne Eckert ${ }^{2}$, Reto W. Kressig3 \\ ${ }^{1}$ Analyze \& Realize GmbH, Berlin, Germany \\ ${ }^{2}$ Transfaculty Research Platform Molecular \& Cognitive Neuroscience, and Psychiatric University Clinics, Basel University, \\ Basel, Switzerland \\ ${ }^{3}$ Department of Geriatric Medicine Felix Platter, Basel University, Basel, Switzerland \\ Email: `JGruenwald@a-r.com
}

How to cite this paper: Gruenwald, J., Eckert, A. and Kressig, R.W. (2020) The Effects of Standardized Ginkgo Biloba Extracts (GBE) on Subjective Cognitive Decline (SCD) in Middle-Aged Adults: A Review. Advances in Aging Research, 9, 45-65. https://doi.org/10.4236/aar.2020.93005

Received: March 31, 2020

Accepted: May 26, 2020

Published: May 29, 2020

Copyright $(9) 2020$ by author(s) and Scientific Research Publishing Inc. This work is licensed under the Creative Commons Attribution International License (CC BY 4.0).

http://creativecommons.org/licenses/by/4.0/

\begin{abstract}
Subjective cognitive decline (SCD) is defined as the presence of self-reported cognitive complaints with unimpaired performance in neuropsychological cognitive tests. SCD has been identified as a precursor of mild cognitive impairment (MCI) and potentially represents the earliest clinical sign of Alzheimer's disease (AD). Standardized extracts of Ginkgo biloba (GBE) are widely used as a treatment for cognitive impairment. Nonetheless, most of the available review articles focus on the effects of GBE in MCI and dementia but not in SCD and its specific cognitive effects. Thus, this review collects and discusses the available published clinical data for the effects of standardized GBE on the early stages of cognitive decline among an age group where SCD becomes a topic-the middle-aged adults. Randomized clinical trials (RCTs), systematic reviews and meta-analyses of standardized GBEs in cognitive decline subjects were searched using PubMed/MEDLINE, Science direct, Cochrane, and Google Scholar until January 2019. Data from relevant RCT were critically evaluated to determine the potential effects of GBE on SCD. The results showed that the number of available GBE studies on SCD is small. Eight studies were selected in which subjects reported memory impairment, in some cases with concerns (worries), and with an average age at onset SCD of 60 years. Six studies gave a proof of efficacy for GBE for the treatment of SCD in at least one cognitive parameter. One study is inconclusive, however, a post-hoc analysis demonstrates efficacy in preventing $\mathrm{AD}$ with intake $>4$ years. The most common GBE dosage used was $240 \mathrm{mg}$ GBE/day over a minimum period of 8 weeks. Hence, there might be beneficial effects of GBE to prevent, improve or delay SCD in the generation of 50 years or older. How-
\end{abstract}


ever, larger, well-defined RCTs using SCD criteria are necessary to further substantiate this effect in SCD subjects.

\section{Keywords}

Subjective Cognitive Decline (SCD), Memory, Ginkgo Biloba Standardized Extract(s) (GBE), LI1370, EGb 761

\section{Introduction}

\subsection{Subjective Cognitive Decline}

Subjective cognitive decline (SCD) has been defined as the presence of self-reported cognitive complaints with unimpaired performance in routinely used neuropsychological cognitive tests [1]. SCD is an important predictor of memory decline in older age: Individuals with SCD represent a significant sample of the population worldwide, and they are at a potentially increased risk of developing objective cognitive impairment [2]. In a large population-based study conducted in Germany which included non-demented adults aged 40 - 79 years, the prevalence for memory-related subjective cognitive symptoms was found to be $53.0 \%$ [3]. This is in line with similar findings from two other community-based studies conducted in Norway [4] and France [5].

Evidence suggests that SCD may represent the first symptomatic manifestation of Alzheimer's disease (AD), but it is also a common complaint at an older age, independent of $\mathrm{AD}$ [2] [6]. In $\mathrm{SCD}$, the apparently felt subtle cognitive decline is not detectable with existing standardized cognition tests, which might be at least partially associated with successful compensation that translates to unimpaired performance levels on individual tests [1].

A recent meta-analysis concluded that about $25 \%$ of cognitively healthy older adults who report SCD will develop mild cognitive impairment (MCI) due to $\mathrm{AD}$ in the next 4 years [7]. Moreover, compared to those individuals without subjective decline, these individuals have a roughly 2 times more likely annual conversion rate of SCD to dementia (2.33\%). Furthermore, in a large cohort study among unimpaired elderly subjects (above 75 years old) over 8 years, the report of subjective memory decline at baseline levels was correlated with an accelerated decline in episodic memory. This decline was more pronounced in subjects with concerns $(\mathrm{SCD}+\mathrm{C})$. These differences remained after adjustment for age, gender, Apo $\varepsilon 4$ status, and education. Also, in subjects free of SCD at baseline, the incidence of SCD was preceded by a decline in delayed recall memory. For delayed recall as well as for verbal fluency, the slope of decline in the 4.5 years before incident SCD was stronger in both the SCD without concern $(\mathrm{SCD}-\mathrm{C})$ and the SCD with concern $(\mathrm{SCD}+\mathrm{C})$ groups [8]. However, the risk of SCD individuals developing dementia was shown to be greater among younger subjects (65 - 75 years) than among older subjects ( $>75$ years) [9]. 
The variability in assessment methods, specifically the manner in which questions and response options are phrased, plays an important role in determining the rates of SCD [10]. Additionally, there has been a lack of consistency in clinical trials. Different research concepts have been used to assess SCD, making it difficult to compare results across clinical and research studies. Also the term SCD, first described in 1982 [11], has been given different terminologies such as subjective cognitive impairment, subjective memory decline, and subjective memory impairment, among others.

A SCD initiative (SCD-I) was launched in 2012 with the aim to facilitate the development of a common SCD research concept based on standardized definitions. Hence, the SCD-I working group, which is an international expert consortium, suggested a conceptual framework for investigating SCD, including research criteria and features which should be reported in SCD studies (for a full overview of these features see [1]). They proposed SCD to be considered as stage 3 of preclinical $\mathrm{AD}$, meaning the stage in which the first changes in cognition emerge before MCI is detected. Additional features were also listed under the term "SCD plus," to further increase the likelihood of identifying preclinical AD [1]. Thus, SCD-I proposed the following criteria for pre-mild cognitive impairment SCD [1]:

1) Subjects have to self-experience persistent decline in cognitive capacity in comparison with a previous normal status and unrelated to an acute event;

2) Subjects have normal age-, gender- and education-adjusted performance on standardized cognitive tests used to classify MCI or prodromal AD.

Both criteria, 1 and 2, must be present, and the following exclusion criteria must be considered:

- $\mathrm{MCI}$, prodromal AD and dementia.

- The criteria can be explained by the presence of a psychiatric or neurological disease, a medical disorder, or a medication or substance use.

Additionally, SCD-I suggested a set of further criteria referred to as SCD plus, which increases, according to current knowledge, the likelihood of an individual with SCD being at the preclinical state of AD. These include:

- Subjective decline in memory rather than in other domains of cognition.

- Onset of SDC within the last 5 years.

- Age at onset of SCD higher than 60 years.

- Concerns associated with SCD.

- Feeling of worse performance than others of the same age group.

Also, if available or possible to obtain in the respective study:

- Confirmation of cognitive decline by an informant.

- Presence of the APOE $\varepsilon 4$ genotype.

- Biomarker evidence for AD.

In parallel, the US National Institute on Aging-Alzheimer's Association (NIAAA) group presented recommendations for identifying "the preclinical stage of $\mathrm{AD}$ ", a stage that is characterized by the presence of biomarker signs of $\mathrm{AD}$ but 
an absence of verified cognitive impairment. Both the NIA-AA stages and SCD/ SCD plus are recent concepts that require continuous refinement and validation in order to predict cognitive decline and AD-type dementia (ADD) [12]. Although not everyone with SCD will show progression, individuals with SCD are ideal candidates for preventive interventions aimed at delaying and/or preventing the onset of $\mathrm{AD}$ [2]. Nevertheless, and despite the outstanding clinical value of SCD, there are still considerable SCD research limitations due to the heterogeneity of definitions, different approaches for measuring SCD (i.e. sample recruitment: clinical vs. community-based), varying operational criteria and $\mathrm{cu}$ toffs as well as the inclusion of the temporal stability of complaints over time [13] [14].

\subsection{Ginkgo Biloba}

Ginkgo biloba L, also known as maidenhair tree, has been used in China as a traditional medicine for various disorders. Ginkgo biloba products are available in various specifications. In Europe, the standardized extract of ginkgo biloba leaf (GBE) is an herbal medicinal drug for the symptomatic treatment of age-related cognitive decline/impairment including memory and concentrations problems, as well as for tinnitus, vertigo and claudicatio intermittens.

According to the EU Pharmacopeia, the dry extract of Ginkgo leaf is standardized to $22 \%$ - $27 \%$ flavonoids, expressed as flavone glycosides, $2.6 \%-3.2 \%$ bilobalides, $2.8 \%-3.4 \%$ ginkgolides A, B and C, and a content of ginkgolic acids below 5 ppm.

The mechanism of action is linked to the different components of the extract. These components are involved in the restoration of impaired mitochondrial function by improving neuronal energy supply, reducing the quantity of oxygen free radicals termed reactive oxygen species (ROS), inhibiting the aggregation and toxicity of amyloid- $\beta(\mathrm{A} \beta)$ protein as well as improving synaptic function and plasticity, which is certainly the major mechanism of action of GBE [15] [16] [17] [18]. Only few effects seem to be independent of the improvement of mitochondrial function, such as the increase in the local cerebral blood flow, reduction of blood viscosity, as well as the modification of neurotransmitter systems-a small effect on the improvement of the dopaminergic and noradrenergic neurotransmission [18] [19]. GBE can therefore be considered a multi-target drug. It is conceivable that all those mechanisms together might be able to reduce the effects of neuronal damage associated with or induced by aging or dementia and thus prevent or at least delay the onset of SCD.

A large number of clinical trials has been conducted with GBE to determine its effects on cognition, but the outcomes are still not clear. Several systematic reviews and meta-analyses evaluated the effect of GBE on cognition, with the main focus on MCI and dementia [17] [20] [21] [22] [23]. In a systematic review on patients suffering from dementia with mild to moderate behavioral symptoms, GBE at a daily dose of $240 \mathrm{mg}$ showed significant benefits on cognition, 
activities of daily living, behavioral symptoms and clinical global impression [23]. When considering quality of life (QoL), only the subgroup with vascular dementia $(\mathrm{VaD})$ did not show statistically significant superiority of the GBE. The QoL results for probable $\mathrm{AD}$, probable vascular dementia, and mixed dementia were significant positive for Ginkgo [23]. Similar results were reported by Savaskan and colleagues [22], where GBE was effective in the treatment of behavioral and psychological symptoms of dementia (BPSD) in patients with mild to moderate dementia. Another systematic review [21] concluded that there is a clear evidence to support GBE for MCI and dementia, but there are inconclusive results over the preventative effect of Ginkgo on cognitive function decline. The overall efficacy was demonstrated when a daily dose of $240 \mathrm{mg}$ was applied [21]. This is similar to what was concluded by Yuan and colleagues [20], where a dose greater than $200 \mathrm{mg} /$ day of GBE for at least 5 months was necessary to support the beneficial effects in people with dementia. In contrast, an early Cochrane Review concluded that GBE appears to be safe, but the evidence to support the beneficial effect in people with dementia of any degree of severity or cognitive impairment is inconsistent and unreliable [15]. As reported above, most of the systematic reviews and meta-analyses focus on dementia and MCI, but limited information is reported on SCD.

A recent overview of systematic reviews on GBE indicated that only two systematic reviews had mentioned prevention of cognitive function decline in dementia or AD and that the results were not significant [21]. The included studies were conducted with both MCI and healthy individuals [24], as well as adults over the age of 70 years who spontaneously reported memory complaints to their primary care physician [25]. According to Zhang and colleagues [21] one of these studies had an extremely low compliance rate [24] while the other was inconclusive [25]. Additionally, the overall conversion rate to dementia in both studies was too low to draw conclusions on the efficacy of Ginkgo. Thus, the subjectivity in cognition still faces important methodological issues.

Four reviews assessed the effects of GBE on healthy individuals, two of them being comprehensive reviews [26] [27], one a systematic review [28], and another a meta-analysis [29]. According to Laws and colleagues [29], GBE had no significant impact on memory, executive function, or attention in healthy individuals of different age groups. Similarly, Canter and Ernst [28], reported that there was no convincing evidence from randomized clinical trials for a robust positive effect of GBE. This was stated for both acute and long-term administration upon any aspect of cognitive function in healthy young people (range from 18 to 59 years old). However, two other reviews stated the opposite. When the neuropsychological effects of chronic administration of GBE in healthy and cognitively impaired subjects of any age were analyzed [26], some evidence was found for a specific pattern of improvement in clinical trials using GBE. This was indicated by an improvement of selective attention, some executive processes, and longterm memory for verbal and non-verbal material through the chronic adminis- 
tration of Ginkgo. Similarly, Crews et al. [27] examined the acute or short-term to long-term neuropsychological efficacy of Ginkgo in sixteen studies. They reported significant positive results in eleven studies with Ginkgo biloba extracts. Despite inconsistencies, the authors reported that the most common positive neuropsychological effects reported for Ginkgo across these studies, which involved healthy and cognitively intact participants, were enhanced performance on tasks assessing aspects of memory, attention, and speed of processing abilities. Furthermore, an expert meeting on "The Ageing Brain" [30] concluded that the symptomatic efficacy of GBE against dementia and MCI has been demonstrated. They also pointed out, that interpretation of data from dementia prevention trials is complicated by important methodological issues. Still, GBE is a multi-target compound with activity on distinct pathophysiological pathways in $\mathrm{AD}$ and age-related cognitive decline. One of the reasons for contradictory clinical findings might be related to the methodology of selection, application, and interpretation of the cognitive outcomes measured [26]. An example of this dilemma is the already mentioned Cochrane review [15]. Here, the authors analyzed the same outcome for different stages of impairment (MCI, AD or vascular dementia (VD)) and included studies with unspecific dementia diagnoses. Moreover, one study also included, apart from standardized GBE, low-dose, low quality extracts [18], which, as to be expected, reported no clinical beneficial effects for ginkgo extracts.

As previously mentioned, several reviews have been conducted, providing quite conflicting conclusions. Moreover, effects in healthy individuals might be hard to determine, especially in the younger population. Currently, there is no comprehensive review available summarizing the effect of standardized GBE on SCD. The purpose of this comprehensive review, then, is to provide the latest updates on the efficacy of standardized GBE on SCD.

\section{Material and Methods}

We searched PubMed/MEDLINE, Science direct, Cochrane and Google Scholar until January 2019 for clinical trials, systematic reviews, or meta-analyses reporting randomized controlled clinical trials on the efficacy of Ginkgo biloba on subjective cognitive decline in adults. We selected several search key words to best cover the search. The terms selected were "ginkgo biloba", "LI1370", "EGb 761 ", combined with "subjective cognitive decline", "memory", "prevention", "cognition", "decline". The specific combination strategy is described in Figure 1.

Additional searches were conducted based on the literature available in key randomized clinical trials and/or review papers.

From the selected studies, information on the length of treatment, the daily dose of GBE used, the mean age of the participants, as well as the parameters evaluated per clinical study, was collected and presented in more detail in Table 1 and Table 2. 


\subsection{Inclusion Criteria}

In general terms, our population of interest included subjects with a mean age above 50 years of age with cognitive concerns or complaints but unimpaired performance in simple cognitive tests (i.e., Mini-Mental State Examination $(\mathrm{MMSE})>25)$ [31]. These are very general inclusion criteria; but due to the limited number of clinical studies that fulfil the requirements described by the SCD (for pre-MCI) and SCD plus criteria (see introduction), we decided to include studies in which subjects reported memory impairment, in some cases with concerns (worries), and with an average age at onset for SCD of $>60$ years old.

\subsection{Exclusion Criteria}

Clinical trials that assessed the effect of GBE on AD, dementia, or MCI were excluded from our evaluation. Clinical trials that included participants with an MMSE below 25 and/or participants from a mean age group below 50 years old were also excluded. Trials with combination therapies or focusing on any other condition where decline of cognition was not the target of the study were also not included. We have also eliminated study duplications and studies that did not focus on subjective cognitive decline. Moreover, articles in Chinese and Russian, which resulted from our search strategy, were also excluded due to language limitations.

\section{Results}

\subsection{Search Results and Selection of Included Studies}

We conducted a search on PubMed with the search terms defined above and identified 329 publications. The following diagram (Figure 1) displays the main search string:

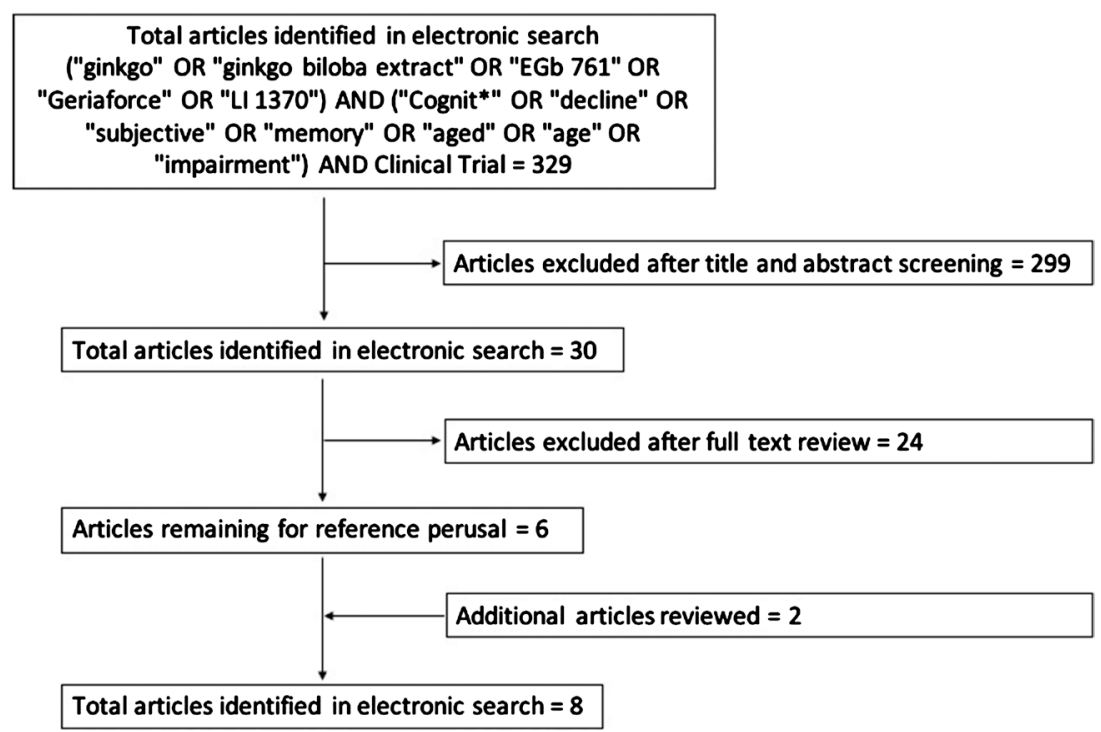

Figure 1. Number of identified studies identified by the search strategy. 
After elimination of duplicates and studies that did not focus on subjective cognitive decline, only six clinical trials met our inclusion/exclusion criteria. Two extra publications were later included after reading key publications. Hence, our review is based on seven randomized, double-blind, placebo-controlled clinical studies (RCT) and one post hoc analysis [32] of an RCT assessing the effect of oral doses of standardized GBE in subjects who spontaneously reported memory complaints or age-related cognitive decline.

An overview of the included studies is given in Table 1, while Table 2 summarizes the major findings of these studies.

\subsection{Identified Studies with SCD Participants}

Identifying studies with SCD subjects was a challenge, as this terminology is not yet well established in clinical trials due to the lack of conceptual and methodological consensus. Hence, our approach to select studies was broader, including subjects with an MMSE above 25 (most of the studies included subjects with a higher MMSE) with self-reported cognitive complaints (showing concerns), mainly related to decline in memory. As discussed in the introduction, and

Table 1. Overview of the selected clinical trials and their features fitting SCD and SCD plus criteria.

\begin{tabular}{|c|c|c|c|c|}
\hline Included Studies & $\begin{array}{l}\text { Length of } \\
\text { treatment }\end{array}$ & Daily Dosage & $\begin{array}{l}\text { Age group of } \\
\text { participants } \\
\text { (mean age) }\end{array}$ & Features fitting $S C D$ and $S C D$ plus criteria \\
\hline $\begin{array}{l}{[33]} \\
\text { (Beck et al., 2016) }\end{array}$ & $\begin{array}{l}\text { short-term } \\
\text { (8 weeks) }\end{array}$ & $240 \mathrm{mg} /$ day standardized GBE & $\begin{array}{l}50 \text { to } 65 \text { years } \\
\text { mean age } 57 \pm 4.6 \\
\text { years }\end{array}$ & $\begin{array}{l}\text { Subjects with subjective memory impairment; } \\
\text { slightly below average cognitive performance; } \\
\text { fitting age group }\end{array}$ \\
\hline $\begin{array}{l}{[34]} \\
\text { (Grass-Kapanke et } \\
\text { al., 2011) }\end{array}$ & $\begin{array}{l}\text { mid-term } \\
\text { (12 weeks) }\end{array}$ & $240 \mathrm{mg} /$ day standardized GBE & $\begin{array}{l}45 \text { to } 65 \text { years } \\
\text { mean age } 55.3 \pm 5.7 \\
\text { years }\end{array}$ & $\begin{array}{l}\text { Subjects with subjective cognitive } \\
\text { impairment incl. memory complaints; } \\
\text { subjects with concerns; perceived } \\
\text { impairment for at least } 3 \text { months; } \\
\text { fitting age group }\end{array}$ \\
\hline $\begin{array}{l}{[35]} \\
\text { (Brautigam et al., } \\
\text { 1998) }\end{array}$ & $\begin{array}{l}\text { mid-term } \\
\text { (24 weeks) }\end{array}$ & $\begin{array}{l}120 \text { drops/day standardized GBE } \\
\text { (ginkgo biloba alcohol/water extract } \\
\text {-Geriaforce) undiluted and diluted } \\
(1: 1)\end{array}$ & $\begin{array}{l}55 \text { to } 86 \text { years } \\
\text { mean age } 68.9 \pm 7.8 \\
\text { years }\end{array}$ & $\begin{array}{l}\text { Subjects who spontaneously reported memory } \\
\text { and non-memory domain complaints; subjects } \\
\text { with concerns; fitting age group }\end{array}$ \\
\hline $\begin{array}{l}{[36]} \\
\text { (Allain et al., 1993) }\end{array}$ & $\begin{array}{l}\text { short-term } \\
\text { (3 weeks) }\end{array}$ & $\begin{array}{l}320 \mathrm{mg} / \text { day or } 600 \mathrm{mg} / \mathrm{day} \\
\text { standardized GBE }\end{array}$ & $\begin{array}{l}60 \text { to } 80 \text { years } \\
\text { mean age } 69.3 \pm 1.2 \\
\text { years }\end{array}$ & $\begin{array}{l}\text { Subjects with mild to moderate memory } \\
\text { impairment; fitting age group }\end{array}$ \\
\hline $\begin{array}{l}{[37]} \\
\text { (Rai et al., 1991) }\end{array}$ & $\begin{array}{l}\text { mid-term } \\
\text { (24 weeks) }\end{array}$ & $120 \mathrm{mg} /$ day standardized GBE & $\begin{array}{l}>50 \text { years } \\
\text { mean age } 73.42 \pm \\
7.25 \text { years }\end{array}$ & $\begin{array}{l}\text { Subjects with mild to moderate memory } \\
\text { impairment; impairment for at least } 3 \text { months; } \\
\text { fitting age group }\end{array}$ \\
\hline
\end{tabular}

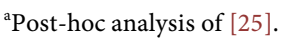


Table 2. Summary of the selected clinical trials.

\begin{tabular}{|c|c|c|c|c|c|c|c|}
\hline Study & $\begin{array}{l}\text { Sample size and } \\
\text { cognition status of } \\
\text { ginkgo group at } \\
\text { baseline }\end{array}$ & Inclusion criteria & Study type & $\begin{array}{l}\text { Age } \\
\text { range/ } \\
\text { Mean age } \\
\text { (years) }\end{array}$ & $\begin{array}{l}\text { Total daily } \\
\text { dose/ } \\
\text { formulation/ } \\
\text { duration }\end{array}$ & $\begin{array}{l}\text { Parameters/ } \\
\text { Measurements }\end{array}$ & Results \\
\hline $\begin{array}{l}\text { [33] Becks } \\
\text { et al., } 2016\end{array}$ & $\begin{array}{l}61(\mathrm{G}=31 ; \mathrm{P}=30) \\
\text { elderly volunteers } \\
\text { with subjective } \\
\text { memory } \\
\text { impairment (SMI) } \\
\text { - PRMQ } 20.1 \pm 3.8 \\
\text { (perspective scale) } \\
\text { - PRMQ } 20.3 \pm 3.0 \\
\text { (retrosp. scale) } \\
\text { - WASI } 105 \pm 6.3 \\
\text { - CERAD-PLUS } \\
1.6 \pm 31.2\end{array}$ & $\begin{array}{l}\text { SMI indicated by at } \\
\text { least one item } \\
\text { answered with "rather } \\
\text { often" or "very often" } \\
\text { or at least five } \\
\text { questions answered } \\
\text { "sometimes" in } \\
\text { PRMQ } \\
\text { WASI IQ scale range } \\
\geq 85 \text { to } \leq 115 \\
\text { CERAD-PLUS with } \\
z \text {-scores range }-1 \text { to } \\
+1 \text { (to age, gender and } \\
\text { educational level) or } \\
z \text {-scores range }-2 \text { to } \\
+1 \text { (maximum of } 3 \\
\text { subtests age, gender } \\
\text { and educational level) }\end{array}$ & $\begin{array}{l}\text { Monocenter, } \\
\text { randomized } \\
\text { double-bind } \\
\text { placebo } \\
\text { controlled }\end{array}$ & $\begin{array}{l}50 \text { to } 65 \\
\text { years } \\
\text { Mean age } \\
\text { in ginkgo } \\
\text { group } 57.5 \\
\pm 4.6 \text { years }\end{array}$ & $\begin{array}{l}\text { EGb } 761 \text { at } \\
240 \mathrm{mg} / \text { day } \\
\text { for } 56 \pm 4 \\
\text { days }\end{array}$ & $\begin{array}{l}\text { Primary goal: evaluate EGb } \\
761 \text { efficacy by behavioral } \\
\text { performance in the cognitive } \\
\text { tasks, fMRI during cognitive } \\
\text { task performance and TSST: } \\
\text { 1) Task-set-switching } \\
\text { (cognitive flexibility) } \\
\text { 2) Go-NoGo task } \\
\text { 3) Delayed-response task } \\
\text { 4) Prospective memory } \\
\text { 5) Daily prospective memory } \\
\text { (postcard) } \\
\text { 6) Task-related fMRI- } \\
\text { BOLD-signals (cognitive } \\
\text { tasks combined with fMRI } \\
\text { 7) The Trier Social Stress-Test } \\
\text { (TSST) } \\
\text { 8) Safety }\end{array}$ & $\begin{array}{l}\text { 1) Task-switch-cost decreased in GBE compared } \\
\text { to placebo (Group } \times \text { Time } \times \text { Switch-Costs } p= \\
0.018 \text {, multiple tests uncorrected), indicating } \\
\text { improved cognitive flexibility } \\
\text { 2) Go-NoGo-task reaction-times corrected for } \\
\text { error-rates indicated a trend for improved } \\
\text { response inhibition ( } \mathrm{p}=0.052 \text { ) } \\
\text { 3) No significant treatment effect detected } \\
\text { 4) No significant treatment effect detected } \\
\text { 5) Only numerically improved performance in } \\
\text { EGb group } \\
\text { 6) No significant treatment effect by fMRI-data (in } \\
\text { all } 4 \text {-task p }>0.05 \text { ) } \\
\text { 7) No significant effect on salivary cortisol } \\
\text { 8) Extract was safe and well tolerated. Most } \\
\text { frequent side effect was headache with higher } \\
\text { prevalence in GBE group (59.4\% versus } 40 \% \\
\text { in placebo) }\end{array}$ \\
\hline $\begin{array}{l}{[32]} \\
\text { Scherrer } \\
\text { et al., } \\
2015^{* *}\end{array}$ & $\begin{array}{l}2854 \\
\text { community-based } \\
\text { elderly subjects } \\
\text { with spontaneous } \\
\text { memory } \\
\text { complaints without } \\
\text { dementia at } \\
\text { inclusion } \\
\text { - MMSE } 27.6 \pm 1.9 \\
\text { - Geriatric } \\
\text { depression scale } 6.7 \\
\pm 4.1\end{array}$ & $\begin{array}{l}\text { Spontaneously } \\
\text { reporting a memory } \\
\text { complaint } \\
\text { MMSE }>25 \text { in GP's } \\
\text { office (in hospital site } \\
\text { MMSE is done as } \\
\text { complementary scale) } \\
\text { Short anxiety battery } \\
\text { test (Covi anxiety } \\
\text { scale) }<6 \text {, (only if } \\
\text { subjects screened at } \\
\text { GP site) } \\
\text { Geriatric depression } \\
\text { scale < } 15 \\
\text { Participants with MCI } \\
\text { were not excluded }\end{array}$ & $\begin{array}{l}\text { Post-hoc } \\
\text { analysis } \\
\text { (GuidAge } \\
\text { study-Vellas } \\
\text { et al. 2012) }\end{array}$ & $\begin{array}{l}\text { aged } \geq 70 \\
\text { years }\end{array}$ & $\begin{array}{l}\text { EGb } 761 \text { at } 2 x \\
120 \mathrm{mg} / \text { day } \\
\text { for } 5 \text { years }\end{array}$ & $\begin{array}{l}\text { Primary goal: to evaluate EGb } \\
761 \text { efficacy on conversion } \\
\text { rate of memory complaint to } \\
\text { dementia of Alzheimer type } \\
\text { 1) Time to event analysis } \\
\text { using Fleming-Harrington } \\
\text { test }\end{array}$ & $\begin{array}{l}\text { 1) The hazard function for conversion to } \\
\text { dementia in the placebo group was } \\
\text { significantly different from that in the GBE } \\
\text { treatment group ( } \mathrm{p}=0.0054) \text {, suggesting a } \\
\text { late effect of EGb } 761\end{array}$ \\
\hline $\begin{array}{l}{[25]} \\
\text { Vellas et } \\
\text { al., } 2012\end{array}$ & $\begin{array}{l}2854(\mathrm{G}=1406 ; \mathrm{P} \\
=1414) \\
\text { community-based } \\
\text { elderly subjects } \\
\text { with spontaneous } \\
\text { memory } \\
\text { complaints to } \\
\text { primary care } \\
\text { practitioner } \\
\text { without dementia } \\
\text { at inclusion } \\
\\
\text { - MMSE } 27.6 \pm 1.9 \\
\text { - Geriatric } \\
\text { depression scale } 6.7 \\
\pm 4.1\end{array}$ & $\begin{array}{l}\text { Spontaneously } \\
\text { reporting a memory } \\
\text { complaint } \\
\text { MMSE }>25 \text { in GP's } \\
\text { office (in hospital site } \\
\text { MMS is done as } \\
\text { complementary scale) } \\
\text { Short anxiety battery } \\
\text { test (Covi anxiety } \\
\text { scale) }<6 \text {, (only if } \\
\text { subjects screened at } \\
\text { GP site) } \\
\text { Geriatric depression } \\
\text { scale < } 15 \\
\text { Participants with MCI } \\
\text { were not excluded }\end{array}$ & $\begin{array}{l}\text { Multicenter, } \\
\text { double bind } \\
\text { randomized } \\
\text { parallel } \\
\text { group } \\
\text { placebo } \\
\text { controlled } \\
\text { (GuidAge } \\
\text { study) }\end{array}$ & $\begin{array}{l}\text { aged } \geq 70 \\
\text { years } \\
\text { Mean age } \\
\text { in ginkgo } \\
\text { group } 76.4 \\
\pm 4.4 \text { years }\end{array}$ & $\begin{array}{l}\text { EGb } 761 \text { at } \\
120 \mathrm{mg} \text { bid for } \\
5 \text { years }\end{array}$ & $\begin{array}{l}\text { Primary outcome: incidence } \\
\text { of AD after } 5 \text { years. } \\
\text { Furthermore: } \\
\text { 1) Annual cognitive, } \\
\text { functional and dementia } \\
\text { assessments by: MMSE, } \\
\text { The Clinical Dementia } \\
\text { Rating (CDR), The Free } \\
\text { and Cued Selective } \\
\text { Reminding Test (FCSRT), } \\
\text { trail making test, verbal } \\
\text { fluency, visual analogue } \\
\text { scales, instrumental } \\
\text { activities of daily living and } \\
\text { geriatric depression scale } \\
\text { 2) Combined incidence of } \\
\text { Alzheimer's disease or } \\
\text { mixed dementia (i.e., } \\
\text { Alzheimer's disease with a } \\
\text { vascular component) } \\
\text { 3) Safety }\end{array}$ & $\begin{array}{l}\text { 1) Primary outcome: After } 5 \text { years } 61 \\
\text { participants (out of } 1406 \text { ) in the ginkgo group } \\
\text { were diagnosed with probable Alzheimer's } \\
\text { disease ( } 1.2 \text { cases per } 100 \text { person-years) } \\
\text { compared with } 73 \text { participants (out of } 1414 \text { ) } \\
\text { in the placebo group ( } 1.4 \text { cases per } 100 \\
\text { person-years; hazard ratio [HR] } 0.84,95 \% \text { CI } \\
0.60 \text { - 1.18; }=0.306 \text {, but the risk was not } \\
\text { proportional over time. } \\
\text { 2) In subgroup analysis significant differences in } \\
\text { Alzheimer's disease incidence were reported } \\
\text { in men, people who consumed alcohol at } \\
\text { baseline, and individuals who received ginkgo } \\
\text { biloba extract for at least } 4 \text { years but this } \\
\text { should be interpreted with caution. } \\
\text { 3) Incidence of adverse events was similar in } \\
\text { both groups } \\
\text { 4) There was a problem with the predefined } \\
\text { statistical test which was chosen assuming } \\
\text { proportional hazards. Hazards were found to } \\
\text { increase during study period } \\
\text { 5) The study was inconclusive due to lower than } \\
\text { expected incidence of Alzheimer's disease; the } \\
\text { GuidAge trial was unable to reach primary } \\
\text { endpoint criterion (decreased conversion to } \\
\text { Alzheimer's disease in } 5 \text { years of follow-up) }\end{array}$ \\
\hline
\end{tabular}




\section{Continued}

\begin{tabular}{|c|c|c|c|c|c|c|c|}
\hline $\begin{array}{l}{[34]} \\
\text { Grass- } \\
\text { Kapanke } \\
\text { et al., } 2011\end{array}$ & $\begin{array}{l}300(\mathrm{G}=149 ; \mathrm{P}= \\
147) \text { subjects with } \\
\text { very mild cognitive } \\
\text { impairment } \\
\text { (vMCI) reported } \\
\text { spontaneously or } \\
\text { upon inquiry; }\end{array}$ & $\begin{array}{l}\text { Perceived cognitive } \\
\text { impairment present } \\
\text { for at least } 3 \text { months } \\
\text { with widely preserved } \\
\text { general cognitive } \\
\text { function, MMSE } \geq 23 \text {, } \\
\text { No indication of } \\
\text { dementia } \\
\text { Intact activities of } \\
\text { daily living by inquiry } \\
\text { (subtle difficulties are } \\
\text { acceptable) } \\
\text { At least one SD worse } \\
\text { than mean of } \\
\text { normative group in at } \\
\text { least one cognitive test } \\
\text { (WMS III Faces I+II, } \\
\text { WTA-ALS, WTS-DT, } \\
\text { TT) }\end{array}$ & $\begin{array}{l}\text { Multicenter, } \\
\text { randomized } \\
\text { double blind } \\
\text { parallel } \\
\text { group } \\
\text { placebo } \\
\text { controlled } \\
\text { (exploratory } \\
\text { ) }\end{array}$ & $\begin{array}{l}\text { range } 45 \text { to } \\
65 \text { years } \\
\text { Mean age } \\
\text { in ginkgo } \\
\text { group } 55.3 \\
\pm 5.7 \text { years }\end{array}$ & $\begin{array}{l}\text { EGb } 761 \text { at } \\
240 \mathrm{mg} / \text { day } \\
\text { for a period of } \\
12 \text { weeks }\end{array}$ & $\begin{array}{l}\text { Primary goal: assess treatment } \\
\text { effects and tolerability of GBE } \\
\text { in subjects below the age of } \\
\text { retirement with very mild } \\
\text { cognitive impairment (vMCI), } \\
\text { also named mild mental } \\
\text { impairment, MMI } \\
\text { 1) Wechsler Memory Scale } \\
\text { III-Faces I and II (WMS } \\
\text { III Faces I+II), } \\
\text { 2) Vienna Test System Work } \\
\text { Performance Series } \\
\text { (Arbeitsleistungsserie, } \\
\text { WTS-ALS) } \\
\text { 3) Vienna Test System } \\
\text { Determination Test } \\
\text { (WTS-DT) } \\
\text { 4) Appointments Test } \\
\text { (Termine Test, TT) } \\
\text { 5) Mental Balance Scale } \\
\text { (Befindlichkeitsskala, BfS') } \\
\text { 6) SF-36 Health Survey }\end{array}$ & $\begin{array}{l}\text { 1) GBE showed better immediate recognition } \\
\text { (WMSIII-Faces I; } \mathrm{p}=0.04 \text { ) and delayed } \\
\text { recognition (WMSM III-Faces II; } \mathrm{p}=0.27 \text { ), } \\
\text { but significant superiority was seen in } \\
\text { subgroup of more impaired subjects (WMS } \\
\text { III-Faces I and WMS III-Faces II, } \mathrm{p}=0.02 \\
\text { and } \mathrm{p}=0.01 \text { respectively). Thus, there is a } \\
\text { trend in favor of EGb in memory. } \\
\text { 2) Significant improvements in concentration } \\
\text { and fatigability (WTS-ALS; } \mathrm{p}=0.01 \text { ) } \\
\text { 3) No significant improvement in attention } \\
\text { (WTS-DT; } \mathrm{p}=0.21 \text { ) } \\
\text { 4) Significant improvement in memory, free and } \\
\text { delay recall (TT immediate recall } \mathrm{p}=0.06 \text { and } \\
\text { TT delayed recall } \mathrm{p}=0.03 \text { ) for the more } \\
\text { distinctly impaired subjects } \\
\text { 5) No effect in mental balance (BfS'; } \mathrm{p}=0.92 \text { ) } \\
\text { 6) Significant improvement in perceived } \\
\text { physical health (SF36; }=0.04 \text { ) but not in } \\
\text { mental health ( } \mathrm{p}=0.15 \text { ) } \\
\text { As an overall, cognitive effects were more } \\
\text { pronounced and more consistent ( } \mathrm{p}<0.025 \text { in } 4 \\
\text { of } 5 \text { tests) in subjects with lower memory } \\
\text { function at baseline }\end{array}$ \\
\hline
\end{tabular}

[35] $241(\mathrm{G}=77(\mathrm{HD})$; Self-reported memory Multicenter, range Geriaforce Primary goal: efficacy and 1$)$ No significant improvement in attention and Brautigam $82(\mathrm{LD}) ; \mathrm{P}=82$ ) and/or concentration randomized 55-86 years (alcohol/water tolerance of two dosages of an et al., 1998 non-institutionaliz con ed elderly individuals with Beck Depression self-reported Inventory score $<21$ memory complaints

Mean MMSE 26.30 \pm 2.31 for $\mathrm{HD}$ and $26.01 \pm 2.54$ for $\mathrm{LD}$

\begin{tabular}{|c|c|c|c|c|c|c|}
\hline $\begin{array}{l}{[36]} \\
\text { Allain } \\
\text { et al., } 1993\end{array}$ & $\begin{array}{l}18(\mathrm{G} 1=18 ; \mathrm{G} 2= \\
18 ; \mathrm{P}=18 ; \text { cross } \\
\text { over study }) \\
\text { elderly subjects } \\
\text { with slightly } \\
\text { age-related } \\
\text { memory } \\
\text { impairment }\end{array}$ & $\begin{array}{l}\text { Non-dement } \\
\text { MMSE range } 25 \text { to } 28 \\
\text { Cognitive impairment } \\
\text { reflected objectively } \\
\text { by a difference of } \\
\text { more than } 1 \text { SD in } \\
\text { comparison with a } \\
\text { group of young } \\
\text { subjects on an } \\
\text { inclusion memory test } \\
\text { (immediate recall of } \\
\text { three lists of words) }\end{array}$ & $\begin{array}{l}\text { Single } \\
\text { center, cross } \\
\text { over, } \\
\text { randomized, } \\
\text { double } \\
\text { blind, } \\
\text { placebo } \\
\text { controlled }\end{array}$ & $\begin{array}{l}\text { range } 60 \text { to } \\
80 \text { yeas } \\
\text { Mean age } \\
\text { in ginkgo } \\
\text { group } 69.3 \\
\pm 1.2 \text { years }\end{array}$ & $\begin{array}{l}\text { EGb } 761 \text { at a } \\
\text { daily dose of } \\
320 \text { mg or } 600 \\
\text { mg over } 3 \\
\text { weeks } \\
\text { (Psychometric } \\
\text { testing started } \\
1 \text { h after } \\
\text { administration) }\end{array}$ & $\begin{array}{l}\text { Primary goal: efficacy } \\
\text { Psychometric battery } \\
\text { (dual-coding test, words and } \\
\text { drawings in relation to } \\
\text { variable presentation times) } \\
\text { 1) Number of correct recalls } \\
\text { of words and drawings } \\
\text { 2) Differences in the number } \\
\text { of drawings and words } \\
\text { recalled correctly (D/W) } \\
\text { 3) Presentation time at which } \\
\text { a break was observed on the } \\
\text { curves }\end{array}$ \\
\hline
\end{tabular}
double blind Mean age extract 3 alcohol/water extract of placebo in ginkgo times/day for ginkgo biloba controlled group 68.924 weeks \pm 7.8 years High dose (HD):40 drops $(1.9 \mathrm{ml})$ undiluted ginkgo extract 2) Benton Test of Visual Low dose Retention-Revised (LD):40 drops (measures short term visual 5) No significant differences in improvement $(1.9 \mathrm{ml}) \quad$ memory),

(ginkgo 3) Rey Test part 1 (measure extract 1:1 short-term memory and with placebo) learning curve)

4) Rey Test part 2 (measures long term memory: recognition)

5) Beck depression inventory

6) Contrast analysis between treatments

7) Side effects

Subjective tests:

8) Subjective perception of memory and concentration (Likert scale) curves concentration (EMCT; p $=0.935)$

Significant improvement of short-term visual

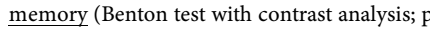
$=0.0076$ )

3) No significant improvement short-term memory and learning curve (Rey Test part 1 $(\mathrm{p}=0.652)$

4) No significant improvement in long term memory recognition (Rey Test part $2(\mathrm{p}=$ 0.246 perception of memory and concentration ( $\mathrm{p}=$ 0.258 ) and for severity of memory complaints, judged by the physicians ( $\mathrm{p}=$ 0.988).

6) Significant differences between the groups: PL $<\mathrm{HD}<\mathrm{LD}(\mathrm{p}=0.0076)$, which suggests that LD (low dose) is the optimal dose.

7) Most frequent side effects were gastrointestinal complaints

8) No relation was found between treatment groups and efficacy and tolerability 1) No significant differences between the
treatments on word recall and drawings 2)No significant differences on $D / W$ differences 3)Significant shift $(\mathrm{p}<0.05)$ towards a shorter presentation time between ginkgo and placebo (break point at $480 \mathrm{~ms}$ and dual coding at 960 $\mathrm{ms}$ VS break point $960 \mathrm{~ms}$ and dual coding beginning at $1920 \mathrm{~ms}$. respectively), thus, there is an improvement in the speed of information processing

1) No significant differences between the
treatments on word recall and drawings
2)No significant differences on $\mathrm{D} / \mathrm{W}$ differences
3)Significant shift $(\mathrm{p}<0.05)$ towards a shorter
presentation time between ginkgo and placebo
(break point at $480 \mathrm{~ms}$ and dual coding at 960
ms VS break point $960 \mathrm{~ms}$ and dual coding
beginning at $1920 \mathrm{~ms}$. respectively), thus, there
is an improvement in the speed of information
processing




\section{Continued}

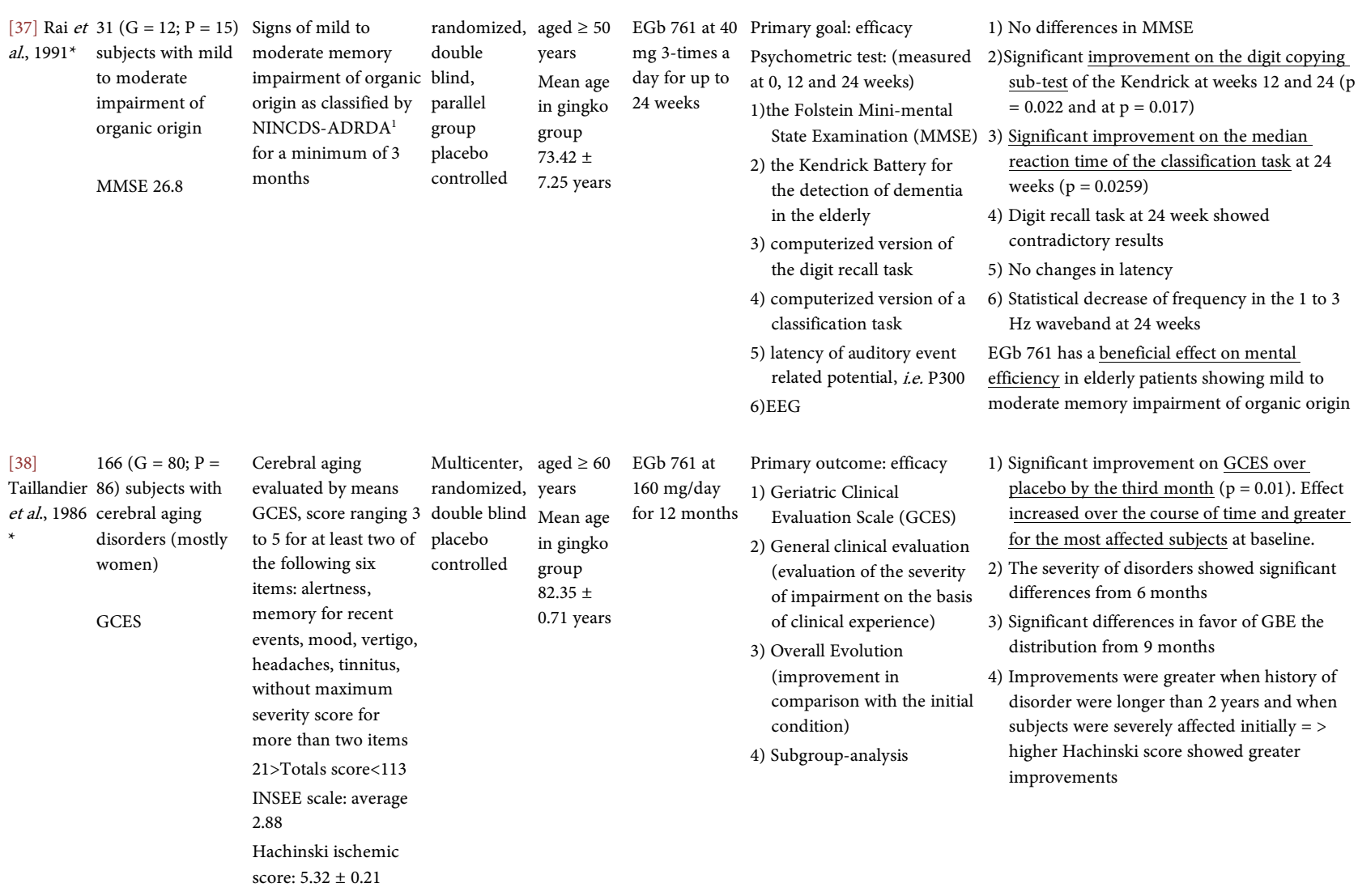

Legend: SMI, Subjective memory impairment; PRMQ, Prospective and Retrospective Memory Questionnaire; WASI, Wechsler Abbreviated Scale of Intelligence; CERAD-PLUS, Consortium to Establish a Registry for Alzheimer's Disease-Neuropsychological Battery (German edition); MMSE, Mini-Mental State Examination; IQCD, Informant Questionnaire on Cognitive Decline in the Elderly; CAMCOG, cognitive part of the Cambridge Mental Disorders of the Elderly Examination; SKT, Syndrom Kurz Test; MACQ, Memory Assessment Clinics Questionnaire; GCES, Geriatric Clinical Evaluation Scale; G: ginkgo group; P: placebo group. 1. The NINCDS-ADRDA Alzheimer's Criteria defines eight cognitive domains which may be impaired in $\mathrm{AD}$ such as memory, language, perceptual skills, attention, constructive abilities, orientation, problem solving and functional abilities. *borderline study; ${ }^{* *}$ This is a post-hoc analysis from study conducted by Vellas et al 2012 . This was a time to event analysis applying the Fleming-Harrington test on the entire set of data.

according to the SCD plus criteria, there are several features that increase the likelihood of preclinical AD in individuals with SCD. These are subjective decline in memory rather than other domains of cognition, onset of SCD within 5 years, age at onset $>60$ years, concerns (worries) associated with SCD, or feelings of worse performance than other groups of the same age group. Based on those qualities, we selected eight studies where at least some of the SCD and SCD plus criteria features were considered for subject inclusion into the clinical studiessee Table 1. The compliance to SCD and SCD plus criteria is stronger in recent clinical studies which were published after the SCD terminology and research concept definition of Jessen and colleagues [1] were established. However, none of the studies included subjects whose information about cognitive decline was supported by an informant, nor was information on the presence of the APOE\&4 genotype or biomarker evidence for $\mathrm{AD}$ provided.

From the selected studies, two studies also enrolled subjects with very mild 
cognitive impairment (vMCI) [34] or subjects with mild-to-moderate memory impairment of organic origin [37]. This illustrates the challenge posed by the high variability of terminology used when reviewing studies for SCD. In the study conducted by Grass-Kapanke and colleagues [34], the MMSE was $27.8 \pm$ 1.5 for the ginkgo group and $27.9 \pm 1.4$ for the placebo group, meaning no cognitive impairment according to MMSE scale. Thus, this study was included in our review. A closer look into the study conducted by Rai and colleagues [37] showed that the MMSE for the ginkgo group was 26.8 while the MMSE for the placebo group was 24.3. Considering that the ginkgo group fulfills our inclusion criteria (MMSE above 25) but the placebo group does not, we considered this study as borderline.

The study conducted by Taillandier and colleagues [38] might also be considered a borderline study. The reason is that it might include elderly individuals with a more severe cognitive impairment than just SCD.

At this point, we would also like to mention that we have excluded from this review five clinical trials assessing the effect of GBE in healthy participants (out of the 24 articles excluded after full text review) [39] [40] [41] [42] [43]. While the age group and MMSE values of the included population in those studies fitted our inclusion criteria, subjects were reported as cognitively intact/healthy subjects. No decline in any cognitive domain was mentioned. We concluded that these participants had no cognitive concerns or any sort of memory impairment and thus did not fit the basis of SCD criteria. Two other studies were excluded because they also included participants with MCI [44] [45].

\subsection{Overview on Different Key Characteristics of the Studies}

The included studies were divided into various evaluated key parameters such as dosage of standardized GBE used, the length of treatment, and the age group of the participants included. An overview of the studies grouped by the evaluated key parameters is provided in the table below (Table 1). In general, two different standardized GBEs were used. The most common dosage of GBE used was 240 $\mathrm{mg}$ /day over a minimum period of 8 weeks. All the studies included adults over 45 years old.

The length of treatments also varied between the selected studies. The treatment duration varied from 3 weeks to 5 years. We divided them into short-term (meaning 3 weeks to 2 months), mid-term (meaning 3 months to 6 months), and long-term (meaning 12 months to 5 years) treatments.

In terms of outcomes measured to evaluate the efficacy of standardized GBE, all the included studies used different psychometric tests to assess cognitive changes. Different cognitive tasks were used to collect information on cognitive parameters such as short-term and long-term memory, cognitive flexibility, reaction time, alertness, attention, mood, MMSE tests, health surveys (SF36), and others. Still, all studies showed positive effects in at least some areas of cognition (see Table 2). 


\section{Discussion}

Here, we present a literature-based current overview on the effects of standardized GBEs on SCD. As mentioned before, SCD can be regarded as an early stage of dementia, a long evolutive process lasting more than a decade. Previous findings report that there are differences in cognitive tests among individuals before they have a confirmed diagnosis of dementia, with differences developing a decade or more earlier. This is followed by a steeper decline three to four years prior to diagnosis. Thus, the pre-dementia phase is divided into different periods of decline: A first stage, with slow cognitive decline, and a second step with a faster decline in a shorter period of time. This probably reflects distinct pathogenic steps [46]. The manifestation onset of SCD occurs ahead of any trackable clinical impairment and there is no age cutoff at the onset. Since the first description of SCD more than 20 years ago, several terminologies have been used in clinical trials, e.g. subjective cognitive impairment, subjective memory decline, memory complaints [1]. This made the selection of studies for this review not a straightforward process. SCD awareness as a risk factor for incidences of dementia is increasing. Standardized GBEs have shown to have specific effects on cognitive functions that extend beyond the improvement of general memory performance.

Based on our inclusion criteria, eight randomized clinical studies were selected. From these, six studies showed positive outcomes in at least one evaluated cognitive parameter [33]-[38] and one study was inconclusive (GuidAge study) [25]. A post hoc analysis of that same study found a delayed effect of conversion to dementia for a subgroup treated with specific standardized GBE for more than 4 years [32]. The comparison between the studies is not straightforward as the studies varied in dose used, duration, and outcomes measured. It is important to mention that none of the selected studies completely fulfilled the SCD or SCD plus criteria features. Although memory complaints might result from many acute psychiatric and/or neurological conditions, the specific scope of SCD lies in its power to detect AD in otherwise still asymptomatic elderly subjects. A possible explanation for the lack of full compliance with both SCD and SCD plus criteria could be attributed and/or linked to the relative juvenile nature of the SCD concept definition and its research area. Nevertheless, and based on the included studies, we evaluated the effect of GBE in SCD based on three key parameters: the dosage of standardized GBE used, the length of treatment, and the age group of the participants.

\subsection{Effects Due to Duration of Treatment}

Half of the included studies used a specific standardized GBE at a dose of 240 $\mathrm{mg} /$ day but treatment periods varied from weeks to years. When given to subjects with SCD for short-term periods (3 weeks to 2 months), GBE showed a positive outcome in terms of cognitive flexibility. The extract improved cognitive flexibility in the absence of significant changes in brain activation, meaning that 
there was no increased recruitment of neural systems and/or resources. Moreover, there was a trend towards speed-accuracy tradeoff in the Go/NoGo task. The authors suggested that GBE might induce mild prefrontal dopaminergic enhancement, but further additional tests are necessary to assess these effects on dopaminergic systems [33]. At higher doses, the same standardized GBE (320 and $600 \mathrm{mg}$ /day) improved the speed of information processing in elderly subjects [36].

Mid-term treatment periods ( 3 to 6 months) with standardized GBE at a dose of $240 \mathrm{mg} /$ day) also induced improvements in cognitive domains including concentration, visual and verbal memory as well as aspects of subjective well-being (physical health) in middle-aged adults (45 to 65 years old) [34]. This is in line with a previous study conducted in patients with more severely impaired cognitive functions. Patients with a diagnosed amnestic mild cognitive impairment (aMCI; MMSE $25.6 \pm 1.3$ in ginkgo group) over the age of 55 years (mean age in ginkgo group $65 \pm 7$ years old) taking a standardized GBE (240 mg/day) for 6 months improved their neuropsychiatric symptoms (NPS) as well as attention, psychomotor speed, and executive functioning. Due to its effects on neuropsychiatric symptoms (NPS) and executive function, GBE treatment significantly improved MCI symptoms, which are known to be associated with faster cognitive decline and a higher risk of developing $\mathrm{AD}$ [45]. Moreover, in patients with MCI taking a GBE $120 \mathrm{mg}$ twice daily for at least 6 months, it was suggested that this might improve dual-task-related gait performance [47]. Lower daily doses of standardized GBE (120 mg/day) also showed beneficial effects on mental efficacy in elderly subjects [37].

When the same dose of a standardized GBE ( $240 \mathrm{mg} /$ day) was used for longterm treatments (over 5 years; GuidAge study) no similar positive results were observed in subjects with spontaneous memory complaints [25]. However, in this study, the power to detect the rate of conversion from memory complaints to $\mathrm{AD}$ was lower than expected, suggesting that detecting statistical significances between the treatments might be difficult (134 detected events versus an anticipated total of 338 events). In a protocol-specified subgroup analysis in which conversion rates were compared for each year of the study, a significant treatment-by-time interaction for the incidence of $A D$ was observed $(p=0.043)$, suggesting that the hazard ratio was not constant over time. Moreover, the post hoc analysis conducted by Scherrer et al. [32] on the same study suggested a delayed effect of standardized GBE on cognitive decline. This is in line with an earlier study conducted by Taillandier and colleagues [38], where the same standardized GBE at a lower daily dose $(160 \mathrm{mg} /$ day $)$ showed significant improvements on the geriatric clinical evaluation scale in elderly subjects.

Considering the variability of treatment schedules used in the trials included in this review, it is difficult to point out which duration of treatment is optimal for observing a positive effect from standardized GBE treatments on cognitive parameters in SCD. We suggest that a period of 6 month minimum (short-term) 
up to years (long-term) would be necessary to ascertain a stronger beneficial effect. However, more clinical trials are needed.

\subsection{Effects Due to Dose}

Based on the included studies, standardized GBEs have shown minimal relevant side effects. Treatment with doses up to $240 \mathrm{mg}$ /day were reported to be safe and well-tolerated. This is in line with a recent systematic review which concluded that standardized GBEs result in an improvement in cognition and daily activities when a dose of $240 \mathrm{mg}$ is used [21] [48]. Similar findings regarding dosage were reported by Yuan and colleagues [20], where a dose greater than 200 $\mathrm{mg} /$ day of GBE for at least 5 months was necessary to support the beneficial effects in people with dementia. It seems that a dose of $240 \mathrm{mg}$ per day of a standardized GBE might be beneficial for SCD.

\subsection{Effects Due to Participants' Age}

The age of the participants might also play a role on the outcomes obtained from the clinical trials. Two studies reported improvement in cognitive functioning and aspects of subjective well-being in SCD participants in the age group between 45 and 65 years. Both studies used the same dose of GBE ( $240 \mathrm{mg} /$ day) for short to mid-term treatments (2 to 3 months) [33] [34]. Positive cognitive effects were also observed for participants with a mean age of 69 years (the age of participants ranged from 55 to 86 years of age) [35] [36], including short-term visual memory as well as improvement of the speed of information. However, the studies used different standardized GBEs (320 and $600 \mathrm{mg} /$ day) [36] and Geriaforce at high and low doses [35]) for short to mid-term schedule treatments (3 weeks and 6 months, respectively).

The remaining four studies included elderly subjects with a mean age above 70 years [25] [32] [37] [38]. Only two of the studies showed beneficial effects on mental efficiency [37] and overall improvement on the geriatric clinical evaluation scale (GCES). The GCES evaluates elderly subjects in an overall manner such as intellectual functions (memory, alertness, attention), mood, social insertion, neurosensorial disturbances [38]. Longer treatment regimens $(240 \mathrm{mg} /$ day of GBE for 5 years) did not reduce the risk of progression to AD in older subjects (mean age of participants $76.3 \pm 4.4$ years) [25]. However, and as mentioned before, the hazard rate for conversion to dementia in the placebo group was significantly different from that in the ginkgo group, which suggests a delayed effect of the extract [25] [32]. In contrast, in a study conducted on normal or mild cognitive impairment in older subjects with a mean age of 79.1 years $(n=3069$; GEM study), the same standardized GBE ( $240 \mathrm{mg}$ /day and a median follow up of 6.1 years) did not reduce cognitive decline in older adults [44]. Additionally, in a pilot study, GBE (240 mg/day) for 3.5 years neither altered the risk of progression from normal to Clinical Dementia Rating $(\mathrm{CDR})=0.5$, nor did it protect against a decline in memory function. It is important to mention that this study 
had limited statistical power, and the population was older than 85 years [49].

A possible explanation why the benefits of GBE are more marked in subjects at a "younger age" (45 to 65 years old) could be because they maintained higher resources to respond with synaptic plasticity than in older subjects. Also, the beneficial effects of GBEs on the cardiovascular system might be less significant at a later age stage as they cannot compensate for the age-related negative changes of the cardiovascular system.

\subsection{Safety Aspects of Standardized GBE}

Based on the included studies and their safety evaluations of standardized GBE, no serious side effects occurred. In all the studies, the extracts had the same safety profile as the placebo treatments. Even long-term administration of standardized GBE (240 mg daily) did not affect vital signs, physical functions, or neurological functions. Thus, the use of standardized GBE, even over long periods of time, is reported to be safe and well-tolerated.

\section{Conclusions}

Due to the highly different studies included in this review, a clear conclusion about the necessary treatment duration or the best recommended age to start the intake of standardized GBE in order to prevent dementia cannot been drawn. Also, apart from one study conducted by Beck and colleagues [33], which followed more closely the SCD and SCD plus criteria features, most of the included studies were published before the SCD definition of Jessen et al., 2014 and thus have limitations regarding the fulfilment of SCD plus criteria. So, there is a clear need for new well-designed clinical studies addressing SCD and standardized GBEs. Although this review has limitations regarding SCD inclusion criteria, it already yields a hypothesis regarding the effect of ginkgo on these early phases of cognitive decline. Firstly, a dose of $240 \mathrm{mg}$ daily seems to be optimal. This dose was reported to be safe and well tolerated. Secondly, long-term treatments of at least 6 months might be necessary to observe beneficial cognitive effects of standardized GBEs on SCD subjects. Finally, standardized GBEs showed positive effects on cognitive flexibility and improved attention and memory (verbal and non-verbal) as well as general well-being in SCD subjects. These effects were stronger in "younger" subjects (between 45 to 65 years old). Despite the positive effects, the clinical evidence on this very specific participant group with no obvious clinical cognitive impairment is still limited to a few trials, thus replication of clinical studies is warranted.

It is important to keep in mind that an international working group is continuously working on research criteria for SCD in the context of preclinical AD. Several methodological issues still need to be addressed before a clear evaluation method for SCD complaints can be developed. SCD is largely based on selfreporting, and there is neither a neuropsychological test score nor any accepted self or observer/informant scale to classify an individual with SCD. Thus, SCD 
assessments vary in research settings, emphasizing the need for harmonized criteria [50]. Subsequently, a constant follow-up of the guidelines is recommended.

\section{Acknowledgements}

The article was financially supported by OM Pharma Switzerland (Vifor SA).

\section{Author Contributions Statement}

JG, EA, and KRW contributed equally to this publication.

\section{Conflicts of Interest}

The authors declare no conflicts of interest regarding the publication of this paper.

\section{References}

[1] Jessen, F., Amariglio, R.E., van Boxtel, M., Breteler, M., et al. (2014) A Conceptual Framework for Research on Subjective Cognitive Decline in Preclinical Alzheimer's Disease. Alzheimer's \& Dementia, 10, 844-852. https://doi.org/10.1016/j.jalz.2014.01.001

[2] Lista, S., Molinuevo, J.L., Cavedo, E., Rami, L., et al. (2015) Evolving Evidence for the Value of Neuroimaging Methods and Biological Markers in Subjects Categorized with Subjective Cognitive Decline. Journal of Alzheimer's Disease, 48, S171-S191. https://doi.org/10.3233/JAD-150202

[3] Luck, T., Roehr, S., Rodriguez, F.S., Schroeter, M.L., et al. (2018) Memory-Related Subjective Cognitive Symptoms in the Adult Population: Prevalence and Associated Factors-Results of the Life-Adult-Study. BMC Psychology, 6, Article No. 23. https://doi.org/10.1186/s40359-018-0236-1

[4] Holmen, J., Langballe, E., Midthjell, K., Holmen, T., et al. (2013) Gender Differences in Subjective Memory Impairment in a General Population: The Hunt Study, Norway. BMC Psychology, 1, Article No. 19. https://doi.org/10.1186/2050-7283-1-19

[5] Singh-Manoux, A., Dugravot, A., Ankri, J., Nabi, H., et al. (2014) Subjective Cognitive Complaints and Mortality: Does the Type of Complaint Matter? Journal of Psychiatric Research, 48, 73-78. https://doi.org/10.1016/j.jpsychires.2013.10.005

[6] Sun, Y., Yang, F.C., Lin, C.P. and Han, Y. (2015) Biochemical and Neuroimaging Studies in Subjective Cognitive Decline: Progress and Perspectives. CNS Neuroscience \& Therapeutics, 21, 768-775. https://doi.org/10.1111/cns.12395

[7] Mitchell, A.J., Beaumont, H., Ferguson, D., Yadegarfar, M., et al. (2014) Risk of Dementia and Mild Cognitive Impairment in Older People with Subjective Memory Complaints: Meta-Analysis. Acta Psychiatrica Scandinavica, 130, 439-451. https://doi.org/10.1111/acps.12336

[8] Koppara, A., Wagner, M., Lange, C., Ernst, A., et al. (2015) Cognitive Performance before and after the Onset of Subjective Cognitive Decline in Old Age. Alzheimer's \& Dementia, 1, 194-205. https://doi.org/10.1016/j.dadm.2015.02.005

[9] Wang, L., van Belle, G., Crane, P.K., Kukull, W.A., et al. (2004) Subjective Memory Deterioration and Future Dementia in People Aged 65 and Older. Journal of the American Geriatrics Society, 52, 2045-2051. https://doi.org/10.1111/j.1532-5415.2004.52568.x

[10] Tales, A., Jessen, F., Butler, C., Wilcock, G., et al. (2015) Subjective Cognitive De- 
cline. Journal of Alzheimer's Disease, 48, S1-S3.

https://doi.org/10.3233/JAD-150719

[11] Reisberg, B., Ferris, S.H., de Leon, M.J. and Crook, T. (1982) The Global Deterioration Scale for Assessment of Primary Degenerative Dementia. American Journal of Psychiatry, 139, 1136-1139. https://doi.org/10.1176/ajp.139.9.1136

[12] Eckerstrom, M., Gothlin, M., Rolstad, S., Hessen, E., et al. (2017) Longitudinal Evaluation of Criteria for Subjective Cognitive Decline and Preclinical Alzheimer's Disease in a Memory Clinic Sample. Alzheimer's \& Dementia, 8, 96-107. https://doi.org/10.1016/j.dadm.2017.04.006

[13] Ávila-Villanueva, M. and Fernández-Blázquez, M.A. (2017) Subjective Cognitive Decline as a Preclinical Marker for Alzheimer's Disease: The Challenge of Stability Over Time. Frontiers in Aging Neuroscience, 9, 377. https://doi.org/10.1016/j.dadm.2017.04.006

[14] Rabin, L.A., Smart, C.M., Crane, P.K., Amariglio, R.E., et al. (2015) Subjective Cognitive Decline in Older Adults: An Overview of Self-Report Measures Used across 19 International Research Studies. Journal of Alzheimer's Disease, 48, S63-S86. https://doi.org/10.3233/JAD-150154

[15] Birks, J. and Grimley Evans, J. (2009) Ginkgo biloba for Cognitive Impairment and Dementia. Cochrane Database of Systematic Reviews, No. 2, CD003120. https://doi.org/10.1002/14651858.CD003120.pub3

[16] Zuo, W., Yan, F., Zhang, B., Li, J., et al. (2017) Advances in the Studies of Ginkgo biloba Leaves Extract on Aging-Related Diseases. Aging and Disease, 8, 812-826. https://doi.org/10.14336/AD.2017.0615

[17] Gauthier, S. and Schlaefke, S. (2014) Efficacy and Tolerability of Ginkgo biloba Extract EGb 761 in Dementia: A Systematic Review and Meta-Analysis of Randomized Placebo-Controlled Trials. Clinical Interventions in Aging, 9, 2065-2077. https://doi.org/10.2147/CIA.S72728

[18] Muller, W.E., Eckert, A., Eckert, G.P., Fink, H., et al. (2017) Therapeutic Efficacy of the Ginkgo Special Extract EGb761(R) within the Framework of the Mitochondrial Cascade Hypothesis of Alzheimer's Disease. World Journal of Biological Psychiatry, 2, 1-17. https://doi.org/10.1080/15622975.2017.1308552

[19] Ahlemeyer, B. and Krieglstein, J. (2003) Neuroprotective Effects of Ginkgo biloba Extract. Cellular and Molecular Life Sciences, 60, 1779-1792. https://doi.org/10.1007/s00018-003-3080-1

[20] Yuan, Q., Wang, C.W., Shi, J. and Lin, Z.X. (2017) Effects of Ginkgo biloba on Dementia: An Overview of Systematic Reviews. Journal of Ethnopharmacology, 195, 1-9. https://doi.org/10.1016/j.jep.2016.12.005

[21] Zhang, H.F., Huang, L.B., Zhong, Y.B., Zhou, Q.H., et al. (2016) An Overview of Systematic Reviews of Ginkgo biloba Extracts for Mild Cognitive Impairment and Dementia. Frontiers in Aging Neuroscience, 8, 276. https://doi.org/10.3389/fnagi.2016.00276

[22] Savaskan, E., Mueller, H., Hoerr, R., von Gunten, A., et al. (2017) Treatment Effects of Ginkgo biloba Extract EGb 761(R) on the Spectrum of Behavioral and Psychological Symptoms of Dementia: Meta-Analysis of Randomized Controlled Trials. International Psychogeriatrics, 30, 285-293. https://doi.org/10.1017/S1041610217001892

[23] von Gunten, A., Schlaefke, S. and Uberla, K. (2016) Efficacy of Ginkgo biloba Extract EGb 761(R) in Dementia with Behavioural and Psychological Symptoms: A Systematic Review. World Journal of Biological Psychiatry, 17, 622-633. 
https://doi.org/10.3109/15622975.2015.1066513

[24] DeKosky, S.T., Williamson, J.D., Fitzpatrick, A.L., Kronmal, R.A., et al. (2008) Ginkgo biloba for Prevention of Dementia: A Randomized Controlled Trial. JAMA, 300, 2253-2262. https://doi.org/10.1001/jama.2008.683

[25] Vellas, B., Coley, N., Ousset, P.J., Berrut, G., et al. (2012) Long-Term Use of Standardised Ginkgo biloba Extract for the Prevention of Alzheimer's Disease (GuidAge): A Randomised Placebo-Controlled Trial. The Lancet Neurology, 11, 851-859. https://doi.org/10.1016/S1474-4422(12)70206-5

[26] Kaschel, R. (2009) Ginkgo biloba: Specificity of Neuropsychological Improvement-A Selective Review in Search of Differential Effects. Human Psychopharmacology, 24, 345-370. https://doi.org/10.1002/hup.1037

[27] Crews, W.D., Harrison, D.W., Griffin, M.L., Falwell, K.D., et al. (2005) The Neuropsychological Efficacy of Ginkgo Preparations in Healthy and Cognitively Intact Adults: A Comprehensive Review. HerbalGram-The Journal of the American Botanical Council, 67, 43-62.

[28] Canter, P.H. and Ernst, E. (2007) Ginkgo biloba Is Not a Smart Drug: An Updated Systematic Review of Randomised Clinical Trials Testing the Nootropic Effects of G. biloba Extracts in Healthy People. Human Psychopharmacology, 22, 265-278. https://doi.org/10.1002/hup.843

[29] Laws, K.R., Sweetnam, H. and Kondel, T.K. (2012) Is Ginkgo biloba a Cognitive Enhancer in Healthy Individuals? A Meta-Analysis. Human Psychopharmacology, 27, 527-533. https://doi.org/10.1002/hup.2259

[30] Lautenschlager, N.T., Ihl, R. and Muller, W.E. (2012) Ginkgo biloba Extract EGb 761 in the Context of Current Developments in the Diagnosis and Treatment of Age-Related Cognitive Decline and Alzheimer's Disease: A Research Perspective. International Psychogeriatrics, 24, S46-S50. https://doi.org/10.1017/S1041610212001019

[31] Creavin, S.T., Wisniewski, S., Noel-Storr, A.H., Trevelyan, C.M., et al. (2016) Mini-Mental State Examination (MMSE) for the Detection of Dementia in Clinically Unevaluated People Aged 65 and over in Community and Primary Care Populations. Cochrane Database of Systematic Reviews, 1, CD011145. https://doi.org/10.1002/14651858.CD011145.pub2

[32] Scherrer, B., Andrieu, S., Ousset, P.J., Berrut, G., et al. (2015) Analysing Time to Event Data in Dementia Prevention Trials: The Example of the GuidAge Study of EGb761. The Journal of Nutrition, Health and Aging, 19, 1009-1011. https://doi.org/10.1007/s12603-015-0661-2

[33] Beck, S.M., Ruge, H., Schindler, C., Burkart, M., et al. (2016) Effects of Ginkgo biloba Extract EGb 761 on Cognitive Control Functions, Mental Activity of the Prefrontal Cortex and Stress Reactivity in Elderly Adults with Subjective Memory Impairment: A Randomized Double-Blind Placebo-Controlled Trial. Human Psychopharmacology, 31, 227-242. https://doi.org/10.1002/hup.2534

[34] Grass-Kapanke, B., Busmane, A., Lasmanis, A., Hoerr, R., et al. (2011) Effects of Ginkgo biloba Special Extract EGb $761^{\circledR}$ in Very Mild Cognitive Impairment (vMCI). Neuroscience \& Medicine, 2, 48-56. https://doi.org/10.4236/nm.2011.21007

[35] Brautigam, M.R., Blommaert, F.A., Verleye, G., Castermans, J., et al. (1998) Treatment of Age-Related Memory Complaints with Ginkgo biloba Extract: A Randomized Double Blind Placebo-Controlled Study. Phytomedicine, 5, 425-434. https://doi.org/10.1016/S0944-7113(98)80038-X

[36] Allain, H., Raoul, P., Lieury, A., LeCoz, F., et al. (1993) Effect of Two Doses of Ginkgo 
biloba Extract (EGb 761) on the Dual-Coding Test in Elderly Subjects. Clinical Therapeutics, $15,549-558$.

[37] Rai, G.S., Shovlin, C. and Wesnes, K.A. (1991) A Double-Blind, Placebo Controlled Study of Ginkgo biloba Extract ("Tanakan") in Elderly Outpatients with Mild to Moderate Memory Impairment. Current Medical Research and Opinion, 12, 350-355. https://doi.org/10.1185/03007999109111504

[38] Taillandier, J., Ammar, A., Rabourdin, J.P., Ribeyre, J.P., et al. (1986) Treatment of Cerebral Aging and Disease Orders with Ginkgo biloba Extract. A Longitudinal Multicenter Double-Blind Drug vs. Placebo Study. La Presse Médicale, 15, 1583-1587.

[39] Kaschel, R. (2011) Specific Memory Effects of Ginkgo biloba Extract EGb 761 in Middle-Aged Healthy Volunteers. Phytomedicine, 18, 1202-1207.

https://doi.org/10.1016/j.phymed.2011.06.021

[40] Cieza, A., Maier, P. and Poppel, E. (2003) Effects of Ginkgo biloba on Mental Functioning in Healthy Volunteers. Archives of Medical Research, 34, 373-381. https://doi.org/10.1016/j.arcmed.2003.05.001

[41] Solomon, P.R., Adams, F., Silver, A., Zimmer, J., et al. (2002) Ginkgo for Memory Enhancement: A Randomized Controlled Trial. JAMA, 288, 835-840.

https://doi.org/10.1001/jama.288.7.835

[42] Mix, J.A. and Crews, W.D. (2002) A Double-Blind, Placebo-Controlled, Randomized Trial of Ginkgo biloba Extract EGb 761 in a Sample of Cognitively Intact Older Adults: Neuropsychological Findings. Human Psychopharmacology, 17, 267-277. https://doi.org/10.1002/hup.412

[43] Mix, J.A. and Crews, W.D. (2000) An Examination of the Efficacy of Ginkgo biloba Extract EGb761 on the Neuropsychologic Functioning of Cognitively Intact Older Adults. Journal of Alternative and Complementary Medicine (New York, N.Y.), 6, 219-229. https://doi.org/10.1089/acm.2000.6.219

[44] Snitz, B.E., O’Meara, E.S., Carlson, M.C., Arnold, A.M., et al. (2009) Ginkgo biloba for Preventing Cognitive Decline in Older Adults: A Randomized Trial. JAMA, 302, 2663-2670. https://doi.org/10.1001/jama.2009.1913

[45] Gavrilova, S.I., Preuss, U.W., Wong, J.W., Hoerr, R., et al. (2014) Efficacy and Safety of Ginkgo biloba Extract EGb 761 in Mild Cognitive Impairment with Neuropsychiatric Symptoms: A Randomized, Placebo-Controlled, Double-Blind, Multi-Center Trial. International Journal of Geriatric Psychiatry, 29, 1087-1095. https://doi.org/10.1002/gps.4103

[46] Amieva, H., Meillon, C., Helmer, C., Barberger-Gateau, P., et al. (2013) Ginkgo biloba Extract and Long-Term Cognitive Decline: A 20-Year Follow-Up PopulationBased Study. PLoS ONE, 8, e52755. https://doi.org/10.1371/journal.pone.0052755

[47] Gschwind, Y.J., Bridenbaugh, S.A., Reinhard, S., Granacher, U., et al. (2017) Ginkgo biloba Special Extract LI 1370 Improves Dual-Task Walking in Patients with MCI: A Randomised, Double-Blind, Placebo-Controlled Exploratory Study. Aging Clinical and Experimental Research, 29, 609-619. https://doi.org/10.1007/s40520-016-0699-y

[48] Tan, M.S., Yu, J.T., Tan, C.C., Wang, H.F., et al. (2015) Efficacy and Adverse Effects of Ginkgo biloba for Cognitive Impairment and Dementia: A Systematic Review and Meta-Analysis. Journal of Alzheimer's Disease, 43, 589-603. https://doi.org/10.3233/JAD-140837

[49] Dodge, H.H., Zitzelberger, T., Oken, B.S., Howieson, D., et al. (2008) A Randomized Placebo-Controlled Trial of Ginkgo biloba for the Prevention of Cognitive Decline. Neurology, 70, 1809-1817.

https://doi.org/10.1212/01.wnl.0000303814.13509.db 
[50] Molinuevo, J.L., Rabin, L.A., Amariglio, R., Buckley, R., et al. (2017) Implementation of Subjective Cognitive Decline Criteria in Research Studies. Alzheimer's \& Dementia, 13, 296-311. https://doi.org/10.1016/j.jalz.2016.09.012

\section{Abbreviations}

Alzheimer's disease (AD),

Amnestic mild cognitive impairment (aMCI),

Behavioral and psychological symptoms of dementia (BPSD),

Cerebrospinal fluid (CSF),

Mini mental state evaluation (MMSE),

Pre-mild cognitive impairment (pre-MCI),

Subjective cognitive decline (SCD),

Subjective cognitive decline with concerns (SCD+C),

Vascular dementia (VD),

Very mild cognitive impairment (vMCI),

Randomized clinical trials (RCT). 